\section{Conditional Manipulation of Sex Ratios by Ant Workers: A Test of Kin Selection Theory}

\author{
Liselotte Sundström, ${ }^{\star}$ Michel Chapuisat, Laurent Keller
}

Variable queen mating frequencies provide a unique opportunity to study the resolution of worker-queen conflict over sex ratio in social Hymenoptera, because the conflict is maximal in colonies headed by a singly mated queen and is weak or nonexistent in colonies headed by a multiply mated queen. In the wood ant Formica exsecta, workers in colonies with a singly mated queen, but not those in colonies with a multiply mated queen, altered the sex ratio of queen-laid eggs by eliminating males to preferentially raise queens. By this conditional response to queen mating frequency, workers enhance their inclusive fitness.

Social insects provide some of the most striking examples of elaborate cooperative behavior, yet life within colonies also entails conflicts $(1,2)$. For example, in eusocial Hymenoptera such as ants, wasps, and bees, diploid females develop from fertilized eggs and haploid males from unfertilized eggs. As a result, queens are equally related to their sons and daughters, whereas workers are more related to their sisters than to their brothers $(2,3)$. These asymmetries in relatedness suggest that queens should favor an equal investment in both sexes, whereas workers should favor greater investment in females than in males $(2,4)$. Hence, a sex ratio conflict arises between queens and workers $(2,4)$, because workers may enhance their inclusive fitness (5) by altering colony sex ratios in their favor, and in so doing act against the interests of the queen. The resolution of such conflicts provides important insights into the role of kin selection in social evolution (6).

The comparison of sex investment patterns in colonies with different breeding structures has emerged as a powerful test of the queen-worker conflict over sex ratio (6). The relatedness asymmetry (the differential relatedness of workers to female versus male brood) decreases with queen mating frequency and the number of related queens per nest. Theory predicts that workers should rear mainly or only females

L. Sundström, University of Lausanne, IZEA, Bâtiment de Biologie, CH-1015 Lausanne, Switzerland; University of Bern, Ethologische Station Hasli, CH-3032 Hinterkappelen, Switzerland; and University of Aarhus, Department of Genetics and Ecology, DK-8000 Aarhus C, Denmark. M. Chapuisat, University of Lausanne, IZEA, Bâtiment de Biologie, $\mathrm{CH}-1015$ Lausanne, Switzerland, and Museum of Zoology, Palais de Rumine, Case Postale $448, \mathrm{CH}$ 1000 Lausanne 17, Switzerland.

L. Keller, University of Lausanne, IZEA, Bâtiment de Biologie, $\mathrm{CH}-1015$ Lausanne, Switzerland, and University of Bern, Ethologische Station Hasli, CH-3032 Hinterkap pelen, Switzerland.

"To whom correspondence should be addressed at University of Helsinki, Department of Ecology and Systematics, Post Office Box 17, FIN-00014, Helsinki University, Finland. E-mail: liselotte.sundstrom@helsinki.fi

The queen controls the primary sex ratio in colonies with relatedness asymmetries above the population average and should rear mainly males in colonies with relatedness asymmetries below the average (7). Recent empirical studies have demonstrated that the sex ratio of adult males and females correlates with colony relatedness asymmetry, as predicted under worker control, in several bee, wasp, and ant species (8). However, these studies did not demonstrate whether workers indeed manipulated sex ratios or whether a sex ratio conflict between workers and queen was manifest (9). Hence, evidence in favor of relatedness-induced, worker-controlled sex allocation ultimately relies on the demonstration that workers alter colony sex ratios by manipulating that of the eggs supplied by the queen to produce that of the individuals eventually reaching maturity (10). by the proportion of haploid (male) and diploid (female) eggs she lays, but workers may subsequently adjust the sex ratios in their own interest by selective rearing of the
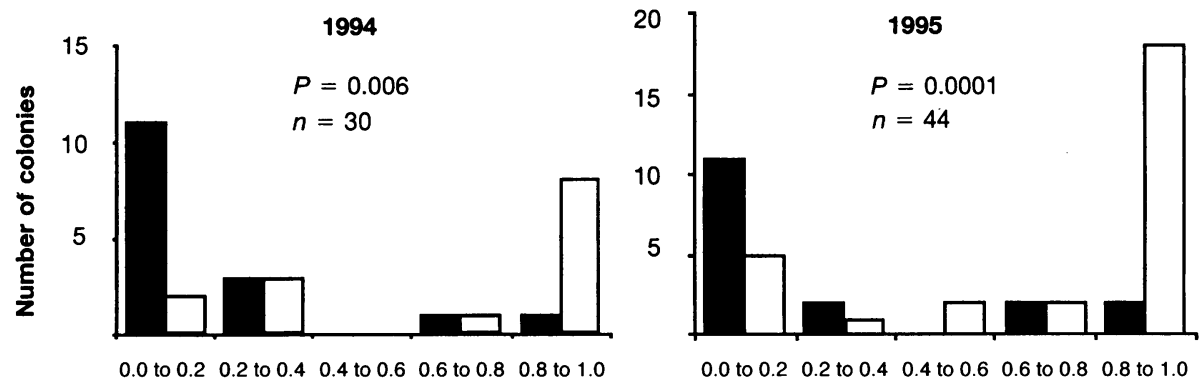

Proportional investment in females

Fig. 1. Sex investment ratios expressed as the proportion of reproductive females in colonies with a singly (white bars) versus multiply (black bars) mated queen (differences were tested with the MannWhitney $U$ test). The dry weights of mature female sexuals $(4.9 \pm 0.4 \mathrm{mg} ; n=20)$ and males $(3.9 \pm 1.0$ $\mathrm{mg} ; n=20$ ) were used to estimate the relative investment in reproductive females and males. Adult sex ratios were assessed from sexual pupae that were sampled from the colonies during 2 to 3 weeks in July. These pupae were reared from eggs laid in April/May when primary sex ratio samples were collected (22). Fifty sexual pupae (or all that were found) were scored per colony (the sex and caste of pupae can be reliably determined by morphology soon after pupation). Colonies were sampled when all sexual brood had pupated, but before any adults eclosed. 
Table 1. Primary (egg) (22) and secondary (pupal) sex ratios expressed as the numerical proportion of reproductive females in colonies headed by a singly or multiply mated queen. Differences between the singly and multiply mated classes of colonies were tested with the Mann-Whitney $U$ test $(n$, number of colonies analyzed).

\begin{tabular}{|c|c|c|c|c|c|c|}
\hline Year & $\begin{array}{l}\text { Singly } \\
\text { mated }\end{array}$ & $n$ & $\begin{array}{l}\text { Multiply } \\
\text { mated }\end{array}$ & $n$ & $U_{1} / U_{2}$ & $P$ \\
\hline \multicolumn{7}{|c|}{ Average proportion of female eggs (mean $\pm S D$ ) } \\
\hline 1994 & $0.43 \pm 0.26$ & 11 & $0.36 \pm 0.27$ & 5 & $31.5 / 23.5$ & $>0.1$ \\
\hline 1995 & $0.43 \pm 0.31$ & 22 & $0.35 \pm 0.26$ & 14 & $220 / 138$ & $>0.1$ \\
\hline \multicolumn{7}{|c|}{ Average proportion of female pupae } \\
\hline 1994 & $0.65 \pm 0.4$ & 14 & $0.20 \pm 0.25$ & 21 & $236 / 38$ & 0.006 \\
\hline 1995 & $0.72 \pm 0.37$ & 28 & $0.22 \pm 0.35$ & 21 & $375 / 72$ & 0.0001 \\
\hline
\end{tabular}

both years of sampling (Table 1).

In striking contrast to the secondary sex ratios, the primary (egg) sex ratios were not significantly different in the two classes of colonies (Table 1). More important, a pairwise comparison of colony-specific primary and secondary sex ratios revealed that the proportion of males decreased significantly between the egg and pupal stages in colonies headed by a singly mated queen in both 1994 and 1995 (Fig. 2) but not in colonies headed by a multiply mated queen.

One explanation for the decrease in the proportion of males between the egg and adult stages could be sex-specific mortality due to deleterious alleles expressed in haploid males (16). This might imply that the observed sex ratio change in the singly mated class of colonies was not mediated by worker actions. However, this scenario fails to explain the association between queen mating frequency and the disappearance of males during brood maturation. Males receive no genetic material from the queen's mate or mates, so the presence of any deleterious alleles is independent of queen mating frequency. Thus, the significant decrease in the proportion of males during brood maturation in colonies with singly

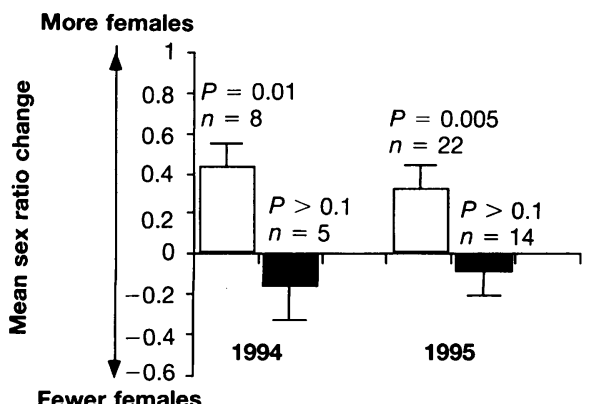

Fig 2. Change in sex ratios between the egg and pupal stages in colonies headed by a singly (white bars) and multiply (black bars) mated queen (mean $\pm \mathrm{SE}$ ). Differences between the egg sex ratio and that of the adults eclosing in the same colonies in July (primary and secondary sex ratios) were compared with nonparametric (Wilcoxon signed-rank) paired tests (23). mated queens can best be explained by workers selectively neglecting or destroying males in these colonies (17). Other factors, such as conditional adaptive responses to localized diseases or parasites (10), are also unlikely, because colonies with different mating frequencies are randomly distributed over the whole area (13) and do not differ significantly in overall productivity (18). Hence, sex ratio specialization and femalebiased population-level sex ratios can in the present case best be explained by a worker response to colony-specific relatedness asymmetries.

These results suggest that in $F$. exsecta a worker-queen conflict is manifest (9) and that female-biased sex ratios are primarily caused by the disappearance of male brood. Furthermore, this response is conditional and is only expressed in colonies headed by a singly mated queen, as predicted by split sex ratio theory (7). By eliminating males, workers preferentially raise the sex that yields the largest marginal fitness-return per unit investment (7), thereby enhancing their inclusive fitness. This implies accurate discriminatory abilities at two stages: First, accurate assessment of queen mating frequency, which suggests great diversity of genetically determined odor cues (19). Second, discrimination between male and female brood relatively early in development, before males are so large that it would be too costly to kill them (20). These findings emphasize the sophistication both of worker reproductive strategies and the recognition abilities on which they often depend (21). More generally, they illuminate some of the complex dynamics between cooperation and ongoing conflicts among members of insect societies.

\section{REFERENCES AND NOTES}

1. E. O. Wilson, The Insect Societies (Harvard Univ. Press, Cambridge, MA, 1971).

2. R. L. Trivers and H. Hare, Science 191, 249 (1976).

3. The haplodiploid sex determination system leads to a threefold relatedness between workers and their sisters $(r=0.75)$ as compared with that between workers and their brothers $(r=0.25)$.

4. E. L. Charnov, Am. Nat. 112, 317 (1978); P. Nonacs, Quart. Rev. Biol. 61, 1 (1986); P. Pamilo, Am
Nat. 137, 83 (1991)

5. Kin selection theory states that individuals can pass on copies of their genes not only by producing offspring but also by helping nondescendent kin, such as siblings, to reproduce. By preferentially favoring their closest kin, organisms can maximize the number of their gene copies transferred to the next generation and thereby their inclusive fitness $\mathrm{W}$. D. Hamilton, J. Theor. Biol. 7, (1964)]

6. A. F. G. Bourke and N. R. Franks, Social Evolution in Ants (Princeton Univ. Press, Princeton, NJ, 1995); R $\mathrm{H}$. Crozier and P. Pamilo, Evolution of Social Insect Colonies, Sex Allocation and Kin Selection (Oxford Univ. Press, Oxford, 1996).

7. J. J. Boomsma and A. Grafen, Evolution 44, 1026 (1990); J. Evol. Biol. 3, 383 (1991).

8. P. S. Ward, Behav. Ecol. Sociobiol. 12, 301 (1983); U. G. Mueller, Science 254, 442 (1991); D. C. Queller, J. E. Strassmann, C. R. Solis, C. R. Hughes, D. M DeLoach, Nature 365, 639 (1993); L. Sundström, ibid. 367, 266 (1994); G. E. Chan and A. F. G. Bourke, Proc. R. Soc. London B 258, 261 (1994); J. D. Evans, Proc. Natl. Acad. Sci. U.S.A. 92, 6514 (1995).

9. F. L. W. Ratnieks and H. K. Reeve, J. Theor. Biol. 208, 33 (1992)

10. P. Sherman and J. S. Shellmann-Reeve, Nature $\mathbf{3 7 0 ,}$ 257 (1994).

11. M van Dijken, Entomol. Exp. Appl. 60, 301 (1991): S Aron, L. Keller, L. Passera, J. Evol. Biol. 7, 403 (1994); L. Keller, G. L'Hoste, F. Balloux, O. Plumey, Anim. Behav. 51, 445 (1996). In Hymenoptera, males are haploid and females are diploid, so the sex of an individual can be assessed on the basis of number of chromosomes.

12. Mating frequency and colony genetic structure were assessed by typing of 20 workers and 10 males (if any were produced) at two microsatellite loci (FL21 with 25 alleles and FL 20 with 2 alleles) [M. Chapuisat, Mol. Ecol. 5, 599 (1996)] and three allozyme loc $\mathrm{Mdh}^{+}, \mathrm{Aco}^{-}$, and $\mathrm{Pgm}^{+}$, each with 2 alleles). When data from all these markers were combined, only $2 \%$ (less than one colony) of double matings may have passed undetected, either because one patriline was not included in the sample or because of identical paternal genotypes at the diagnostic loci. Thirtyfour queens were singly mated, 19 were doubly mated, 2 were triply mated, and 1 had mated with four males. The colonies with a multiply mated queen were combined in the further analyses.

13. The queen mating frequency of the nearest neighbor of any given nest was in accordance with a binomia distribution of singly and multiply mated queens in the population $\left(x^{2}=1.03, \mathrm{df}=1, P>0.2516\right)$.

14. In all, 1209 workers and 503 males were analyzed. All males were haploid, and in all except one colony their genotype was consistent with them being the sons of the queen. The exceptional colony was probably orphaned, because no workers were produced and males of three different genotypes were found (which is consistent with workers producing the males). Furthermore, genotypes of males and workers revealed that two colonies had more than one queen. These three colonies were excluded from all analyses.

15. Colonies headed by one singly mated queen have a higher relatedness asymmetry (3:1) than do colonies headed by a doubly $(2: 1)$ or triply mated queen (1.67: 1).

16. R. H. Crozier, Genetica 41, 551 (1970); R. H. Smith and M. R. Shaw, Nature 287, 728 (1980)

17. S. Aron, E. L. Vargo, L. Passera, Anim. Behav. 49, 749 (1995).

18. The total productivity (total biomass of sexuals plus workers), as determined by mark-recapture [L. Sundström, Am. Nat. 146, 232 (1995)], did not differ significantly between colonies with singly mated queens $(9123 \pm 6323 \mathrm{mg} ; n=20)$ and those with multiply mated queens $\left(12,600 \pm 8232 \mathrm{mg} ; n=10 ; U_{1} / U_{2}=\right.$ $73 / 127, P>0.2)$. The observed mating swarm sex ratio was $65 \%$ females (numerical sex ratio) and $71 \%$ females (investment sex ratio based on dry weights).

19. F. L. W. Ratnieks, Evolution 45, 281 (1991); J. Theor. Biol. 142, 87 (1990): Nat. 145, 969 (1995)

20. P. Nonacs, in Evolution and Diversity of Sex Ratio in Insects and Mites, D. L. Wrensch and M. A. Ebbert, 
Eds. (Chapman Hall, New York, 1993), pp. 384-401. 21. L. Keller and K. G. Ross, Science 260, 1107 (1993).

22. To determine primary sex ratios, approximately 50 eggs (a small fraction of the total number of eggs) were collected at the onset of egg laying, between late April and mid-May, when sexual brood is produced [K. Gösswald, Die Waldameise Vol. 1 (AULA-Verlag, Wiesbaden, Germany, 1989)]. The number of chromosomes $(2 n=52)$ [E. Hauschteck-Jungen, and $\mathrm{H}$. Jungen, Insect Soc. 23, 513 (1976)] was assessed (11) (blind with respect to colony identity and queen mating frequency) in at least 5 but usually 10 cells per egg. The large number of chromosomes sometimes precluded counts of all chromosomes, so eggs in which fewer than 26 chromosomes were consistently found were classified as males, whereas those with more than 40 chromosomes were classified as females. Only nests with at least 20 successfully sexed eggs were included in the analyses, so that two nests in 1994 and three in 1995 were discarded.

23. We made efforts to collect eggs immediately after the onset of egg laying in April/May, when only sexual brood is laid. However, worker-destined eggs are laid from mid-May onward, causing a slight overlap in worker and sexual brood, so a few worker-destined eggs may have been included in the primar sex ratio sample. Hence, the primary sex ratios ob tained here may slightly overestimate the proportion of females among the eggs, and consequently pro vide a conservative test of differences in primary and secondary sex ratios in the singly mated class. The sample sizes differ from those given in Table 1, because three colonies that were scored for primary sex ratios only produced worker brood in 1994

24. We thank J. J. Boomsma, A. F. G. Bourke, W. D. Brown, E. A. Herre, M. Milinski, D. Nash, T. Reuter, F. L. W. Ratnieks, P. Sherman, and three anonymous referees for comments on the manuscript; $C$ Chang, R. Forsman, P. Gertsch, A.-M. Mehmeti, I. Schmidt, and $H$. Åberg for assistance; and Tvärminne Zoological Station in Finland for working facilities. The study was funded by the Academy of Finland; Svenska Kulturfonden; Société Vaudoise des Sciences Naturelles; Swiss National Science Foundation; and Fondation du 450e anniversaire University of Lausanne.

1 July 1996; accepted 13 September 1996

\section{Hypertension Induced in Pregnant Mice by Placental Renin and Maternal Angiotensinogen}

\author{
Eriko Takimoto, Junji Ishida, Fumihiro Sugiyama, \\ Hisashi Horiguchi, Kazuo Murakami, Akiyoshi Fukamizu*
}

Maternal hypertension is a common complication of pregnancy and its pathophysiology is poorly understood. This phenomenon was studied in an animal model by mating transgenic mice expressing components of the human renin-angiotensin system. When transgenic females expressing angiotensinogen were mated with transgenic males expressing renin, the pregnant females displayed a transient elevation of blood pressure in late pregnancy, due to secretion of placental human renin into the maternal circulation. Blood pressure returned to normal levels after delivery of the pups. Histopathologic examination revealed uniform enlargement of glomeruli associated with an increase in urinary protein excretion, myocardial hypertrophy, and necrosis and edema in the placenta. These mice may provide molecular insights into pregnancy-associated hypertension in humans.

Pregnancy induces extensive maternal adaptations in cardiovascular and renal physiology. Circulating levels of renin and angiotensin, proteins that serve as primary regulators of blood pressure and body-fluid volume, markedly increase during pregnancy (1). Although alterations of the reninangiotensin system have long been suspected to contribute to pregnancy-associated hypertension $(2,3)$, the pathogenesis of this hypertension is not clear. The presence of renin in the placenta indicates that there is local renin synthesis (4) and suggests the possible involvement of renin in the regulation of maternal blood pressure and

E. Takimoto, J. Ishida, K. Murakami, A. Fukamizu, Institute of Applied Biochemistry and Tsukuba Advanced Research Alliance (TARA), University of Tsukuba, Ibarak 305, Japan.

F. Sugiyama, Laboratory Animal Research Center, University of Tsukuba, Ibaraki 305, Japan.

$\mathrm{H}$. Horiguchi, Institute of Basic Medical Sciences, University of Tsukuba, Ibaraki 305, Japan.

*To whom correspondence should be addressed. E-mail: akif@sakura.cc.tsukuba.ac.jp uteroplacental vascular resistance and blood flow (5). However, there is no direct in vivo evidence that renin is secreted from the placenta into the maternal circulation or that a paternally derived factor contributes to the regulation of maternal blood pressure.

We have created lines of transgenic mice carrying either the human renin gene (6) or the human angiotensinogen gene (7). These mice were normotensive despite the normal tissue-specific expression pattern of transgenes, but the $F_{1}$ progeny expressing both human genes exhibited a chronic hypertension (8). During the cross-mating experiments, we observed that transgenic female mice carrying the human angiotensinogen gene, which displayed normal blood pressure in the nonpregnant state, developed hypertension at 19 days of gestation, but only when they had been mated with transgenic males carrying the human renin gene (Table 1). Pregnant females derived from other mating combinations did not show hypertension. On the basis of these results, we hypothesized that the combined action of placental renin and maternal angiotensinogen might play a role in the development of pregnancy-associated hypertension.

To test this hypothesis, we conducted a time-course measurement of blood pressure elevation during pregnancy. The blood pressure of the human-angiotensinogen transgenic females mated with the human-renin transgenic males began to increase at 14 days of gestation, continued to rise until the day before delivery, and returned to the level seen in the nonpregnant state by 3 days after delivery (Fig. 1A). In contrast, control mice did not show any change in blood pressure throughout pregnancy.

To examine whether renin derived from male mice carrying the human renin gene is secreted into the maternal circulation, we measured plasma human renin
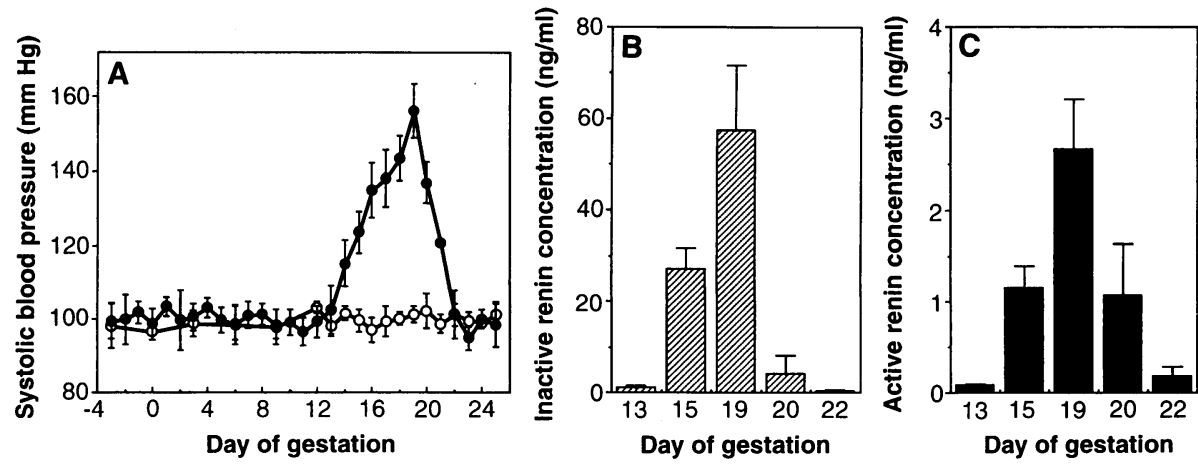

Fig. 1. Systolic blood pressure and human renin concentration in the murine maternal circulation before and during pregnancy, and after delivery. Day 0 is the day of coitus. (A) Changes in systolic blood pressure of pregnant mice. Results are expressed as means \pm SD for each determination (14). Day 20 was the day of delivery and systolic blood pressure was measured afterward. (O) hRN male $\times$ hANG female ( $n=18$ mice); (O) WT $\times$ WT $(n=7$ mice). Changes in inactive $(\mathbf{B})$ and active $(\mathbf{C})$ human renin concentration in the maternal circulation of pregnant mice with hypertension. Values are the means \pm $\mathrm{SD}$. Four animals were used for each determination by radioimmunoassay (15). 